\title{
Computer Assisted E-Laboratory using LabVIEW and Internet-of-Things Platform as Teaching Aids in the Industrial Instrumentation Course
}

\author{
https://doi.org/10.3991/ijoe.v14i12.8992 \\ Muhammad Asraf H. $\left.{ }^{\varpi}\right)$, Nur Dalila K.A., Zakiah M.Y. \\ Universiti Teknologi MARA, Masai, Johor, Malaysia \\ masrafejohor.uitm.edu.my \\ Amar Faiz Z.A. \\ Universiti Teknikal Malaysia Melaka, Durian Tunggal, Melaka, Malaysia \\ Nooritawati M.T. \\ Universiti Teknologi MARA, Shah Alam, Selangor, Malaysia
}

\begin{abstract}
Nowadays, the emerging trend of utilizing the internet technology to improve teaching methods has caught the attention of many researchers. The education sector is the particular sector which has been getting the influence to implement more advanced teaching methods, and this can be seen through the application of the monitoring system, remote control, and even data acquisition through the Internet. Therefore, this study demonstrates the development of the interactive system via the Internet for the remote access to the equipment known as LD-Didactic temperature system which is used in the laboratory. This particular system is developed using an Arduino-Espresso8266 and LabVIEW platform which is integrated with Blynk software in order to remotely control the Proportional, Integral, and Derivative (PID) setting. Furthermore, the proposed framework is specifically focused on the PID temperature control system, which allows students to learn and simulate the concept of the control scheme by adjusting suitable parameter gains. Moreover, the system evaluation demonstrates the functionality and ability of direct controlling, monitoring, and tracking in order to achieve the targeted temperature control. These three strategies ensure the reproducibility of the experiment for the implementation in different systems. Last but not least, the designed system illustrates that full integration of the system with the internet platform provides students with the underlying knowledge of fundamentals, graphic visualization, and simulation practices. These will subsequently facilitate the learning process of the students.
\end{abstract}

Keywords - education; Proportional, Integral, and Derivative (PID) control system; Internet of Things (IoT); remote application; interactive system; virtual laboratory; simulator 


\section{Introduction}

Nowadays, there has been an extensive use of the Internet technology for spreading information or acquiring knowledge. The development of tools which involve the use of Internet technology can be carried out in order to control specific instruments or device. An application known as "Internet of Things (IoT)" has increased the standards of the computer simulation and the remote and virtual laboratory in the engineering education system. Now, with the rapid development of IoT's application, especially in the remote control system [1], the concept of this application can be applied. This development has led to the invention of internet-based applications which are particularly for teaching purposes. Furthermore, an innovative teaching approach has been introduced to the engineering education system in order to keep the students engaged in learning and to improve their understanding of the particular course they take. Although the requirements of utilizing the tools for simulations or laboratory activities have been frequently fulfilled by the conventional education system, catering a substantial number of students would result in the constraint of time, equipment, and laboratory workspace. Moreover, the increasing cost of laboratory equipment and their maintenance hinders the educational institution from obtaining up-to-date laboratory instruments in spite of the fact that equipment users are capable of familiarizing with the concept of practically relating actual experiment results with each other. An experiment, which was conducted through the simulation activity, illustrated the case study of the physical equipment. This experiment has offered a solution for issues regarding the control of the virtual simulation while remotely placing the result away from the physical equipment $[2,4]$. In this study, it was found that the application of IoT in the conventional laboratory provides advantages for students, where they can effectively get themselves engaged in their laboratory activities without being obliged to attend to those activities. Besides, the schedules for the activities can be appropriately set up and arranged outside class hours. This subsequently encourages independent learning among the students. Another advantage which can be obtained from an internet-based system is the unlimited number of students who are able to access the laboratory equipment remotely.

In order to incorporate innovative technology into the conventional remote laboratory, an experimental tool is introduced for a real-time monitoring of temperature. This action involves the use of newly developed and affordable hardware in order to establish the access point between Wi-Fi-enabled devices and the real plant hardware [3]. The real-time monitoring of temperature, which is done through the computer, would enable a proper regulation of temperature when the condition of the system is being checked. Therefore, this study aims to introduce a framework for developing an internet-based access to the conventional laboratory by setting up a remote connection through the Internet. Moreover, the computer-based e-laboratory using LabVIEW is also introduced through this study. Nevertheless, the improvised framework, which is to be implemented in the e-laboratory through the incorporation of the IoT concept has yet to be studied. This framework takes action on the study of PID control scheme in a real-time environment setting while allowing users to access and remotely obtain the measurement using a configurable and low-cost circuitry equipment with a simple interface. Apart from that, it makes investigation conducted by users possible through the 
configuration of the parameters of gains which consist of the proportional, integral, and derivative gains. Each of these gains is denoted by $k_{p}, k_{i}$, and $k_{d}$ respectively, and they determine the system performance. The equipment used consists of several components, such as an Arduino-Espresso8266 as the main microcontroller, LabVIEW platform, and LD-Didactic temperature plant, which serve as the platform of an interactive teaching method which supplements students' learning process. Besides, the flexibility that the system offers to the remote laboratory through the replication of the experiment could contribute to an improved understanding among its users. As a result, the gap between the revised theoretical framework and the actual application can be filled.

\subsection{Internet-based Laboratory in the Education System}

There has been a rapidly growing interest in laboratory development which began in the earlier 2000s. This development has progressed from the conventional to Internetbased platform due to ubiquitous computer advancement. In the recent decades, web platforms are the platforms where users are allowed to interact with a system, and there have been continuous interests for conducting research on this particular topic. Many approaches have been introduced, such as computer simulation tools, virtual laboratories, and remote laboratories, for the sole purpose of enhancing user's learning experience upon the use of these platforms [5]. To be specific, computer simulation is a tool used for replicating experiments without the presence of the actual plant. Furthermore, the parameter is simulated and adjusted to investigate the condition of the system. Meanwhile, virtual laboratories simulate the parameter similar to actual plant in order to place an impact on the developed model. The aforementioned model is represented by a mathematical model, and a connection via the Internet is enabled in order to stimulate a response to the plant. Meanwhile, in respect to the remote laboratories, the particular experiment involved is interfaced with an actual plant in which a remote connection enables the process of interconnecting laboratory equipment with an internetbased system via the server. Moreover, the remote-based laboratory possesses the capability of conducting real-time experiments at a distance apart from the workspace. It is worthy to note that the advantages which can be gained from the web laboratory are that experiments can be repeated, iterative learning opportunities can be created, and students can use them for reflection and self-testing outside class hours. These development tools, which range from basic concepts to those which are more advanced, have been accessible as a great educational support.

\subsection{Literature Review of the Remote Laboratory}

This section covers the available works of literature which were focused on the existing laboratory systems. The summary of the trends in the technologies and development tools are highlighted in Table 1. In 2006, R.Dormido et al. [7] proposed a webbased control lab for a nonlinear MIMO system of a three tank plant. Their contribution in this research was the development of the client side of the virtual laboratory, where a programming support by Easy Java Simulations (EJS) was used in order to develop 
Java applets. This enabled the actual invention of a tank system, either through simulation or a remote access to the plant. Subsequently, in 2010, Lucilia et al. [8] demonstrated the design and implemented the use of the biochemical engineering laboratory. The laboratory provided the fundamental exploration, pre-visualization, and simulation of the chemical reaction which took place in a reactor by determining the residence time variable. Following in 2011, Fabregas et al. [9] revealed the teaching tools for the use of the remote laboratory, specifically the control system via the Simulink and EJS of a ball and hoop as a plant. In this study, an Apache Tomcat web server was required for the development of the remote lab as an applet and the interface of the plant via Data Acquisition (DAQ) with a MATLAB platform. The web server was structured as a single-client-server in which a computer functioned as both the server and controller for the plant. However, compatibility issues were still present in the access to the plant when incompatibility with the DAQ card persisted. A common approach implemented in internet-based laboratories, specifically on the front-ends (i.e. its GUIs, ) was the Easy Java Simulations (EJS) applet. This applet was capable for a direct run of these laboratories from their web pages. Since then, there had been a significant amount of effort and interest paid in the issue of the virtual or remote laboratories in both the educational and industrial sectors. Moreover, Carlos A.J. et al. [10] carried out the virtual development using Java platforms, such as EJS (Easy Java Simulations) and EjsRL, for the modeling and simulation of the laboratories. Furthermore, the educational lab, which was developed for the Robotic and Computer Vision field, was user-friendly. Besides, it consisted of two layers of software architectures which enabled the transmission of data to take place between systems and the presence of graphical interface support. The laboratory experimented on the robotic behaviors of the computer, such as kinematics, dynamics, and programming with the functionality of the remote operation. In addition, the computer vision libraries were added for a convenient processing, reading, and writing of the images. On the other hand, A.Rojko et al. [11] demonstrated the development of the remote laboratory in the mechatronics field through the E-learning Moodle platform. In this study, a group of engineers and technicians who were willing to improve their practical knowledge and skills in mechatronics especially in terms of dealing with real devices were involved. Furthermore, the E-learning modules consisted of several case studies on the servomotor, electrical circuit, and mechatronic devices of the SCARA robot. Based on the evaluation conducted on the respondents, the effectiveness of the modules in complementing their job training and benefiting their careers was demonstrated. Dictino C. et al. [12] have investigated the sensor performance and mapping environment in Mobile Robotics. This laboratory allowed interactions to take place with a real Lego Mindstorms NXT robot via virtual simulation or remotely-conducted controls. These researchers have developed the laboratory architecture which consisted of the client and server side. The internet connection was required in order to interface with both sides which were executed through EJS and MATLAB respectively. On the other hand, J. Sanchez et al. [13] have developed an interactive virtual lab for tubular photobioreactor (PBR) by simulating the evolution of the microalga culture using the Easy Java Simulations as the instruments. This laboratory is beneficial for conducting lessons and research in order to gain an understanding of the basic cultural variables, such as $\mathrm{pH}$, biomass, concentrations, PBR geometry etc. Zhenlei He et al. 
[14] have developed the framework of the Internet-based lab for electrical engineering courses using the client/server/application approach. The instruments involved in this development were as follows; Flex plug-in design, XML communication, and the Modelica simulation for the combination of the virtual and physical experiment via the Internet. It was highlighted by these researchers that this approach could provide either simulations or practical exercises which function in filling the knowledge gap between simulation and theoretical practices, besides enhancing the theoretical understanding. Based on research by Francisco E. [15], a web-based laboratory in Physics and Control Education was carried out using the Easy Java Simulations as tools for the laboratory's modeling and authoring. Various types of the plant were used, including quadrupletank process, superposition wave, electrical charge, robot arm, etc. Moreover, in order to integrate the Java simulation and Moodle course with HTML and other w3C standards, Moodle plug-ins were integrated into the courseware system. Maria L. Botero et al. [16] proposed the development of Cambridge web labs via a web server to remotely control the chemical reactor in the chemical engineering field. The investigation on PID was conducted in order to monitor the proportion of absorbed light and product stream from the reactor. Furthermore, the process control system (PCS7) was used as the controller in order to enable the experiment to remotely control the chemical reactor via the Internet. Meanwhile, P.A. Cotfas et al. [17] proposed the educational lab prototype known as RELab to study on the performance parameter, such as photovoltaic cells, small solar thermal collectors, and mini wind turbines in the effort of achieving renewable solar and wind energy sources. The development tools used LabVIEW and NI Elvis platforms. Meanwhile, a series of recent studies by Wang N. et al. [19, 20] was conducted on the introduction of the remote laboratory, where the Wiki-technology integrated with the web-based application was used. In this research, the PID control technique, which had been implemented in the mechanical engineering course, was demonstrated by the researchers. In addition, the researchers $[18,21]$ also established the remote laboratory which involved the use of mobile application through the framework of Node.js server and Apache's web engine. This framework was used to conduct the experiment in the laboratory, with the objective of controlling the speed of DC motor via the PID controller scheme.

Based on the recent works of literature mentioned in the previous sections, it can be seen that the interest in developing a remote laboratory as a significant support in pedagogy has been increasing these days. The development of the education field has led to a newly developed interest in a remote laboratory, with various framework being proposed [6]. However, the amount of discussions made on the integration of remote lab with the use of the smartphone is scarce. According to researchers, the survey on a similar framework has not been found in any work of research. Nevertheless, the new platform to implement the LabVIEW and IOT methods for on-site and remote monitoring respectively have provided an advantage which can add further improvement to the existing remote laboratory framework. 
Paper-Computer Assisted E-Laboratory using LabVIEW and Internet-of-Things Platform as Teach...

Table 1. Summary of the Technologies Adopted in the Laboratory

\begin{tabular}{|c|c|c|c|}
\hline $\begin{array}{c}\text { Year/ } \\
\text { Author }\end{array}$ & Subjects & Platform & $\begin{array}{c}\text { Type of Labora- } \\
\text { tory }\end{array}$ \\
\hline $\begin{array}{l}(2017) \\
\text { Wang N. et al. }\end{array}$ & $\begin{array}{l}\text { Mechanical engineer- } \\
\text { ing }\end{array}$ & Web 2.0 technology & Remote Lab \\
\hline $\begin{array}{l}(2017) \\
\text { Wang N. et al. }\end{array}$ & $\begin{array}{l}\text { Mechanical engineer- } \\
\text { ing }\end{array}$ & $\begin{array}{l}\text { Node.js server and } \\
\text { Apache web engine }\end{array}$ & Remote Lab \\
\hline $\begin{array}{l}(2016) \\
\text { P.A. and D.T. Cotfas }\end{array}$ & Renewable energy & LabVIEW and NI Elvis & $\begin{array}{l}\text { Hands-on } \\
\text { Remote Lab }\end{array}$ \\
\hline $\begin{array}{l}(2016) \\
\text { Maria L Botero et al. }\end{array}$ & Chemical Engineering & $\begin{array}{l}\text { SIMATIC PCS7(Process Con- } \\
\text { trol System 7) }\end{array}$ & Remote Lab \\
\hline $\begin{array}{l}(2015) \\
\text { Francisco Esquembre }\end{array}$ & Physics and Control & Easy Java/Javascript Simulations & $\begin{array}{l}\text { Computer simula- } \\
\text { tion } \\
\text { Virtual Lab } \\
\text { Remote Lab } \\
\end{array}$ \\
\hline $\begin{array}{l}(2014) \\
\text { Zhenlei He et al. }\end{array}$ & Power electronics & $\begin{array}{l}\text { Flex plug in design, XML com- } \\
\text { munication, and Modelica simu- } \\
\text { lation }\end{array}$ & Virtual Lab \\
\hline $\begin{array}{l}(2013) \\
\text { J.Sanchez et al. }\end{array}$ & $\begin{array}{l}\text { Tubular Photobioreac- } \\
\text { tor }\end{array}$ & Easy Java Simulations & Virtual Lab \\
\hline $\begin{array}{l}(2013) \\
\text { Dictino Chaos et al. }\end{array}$ & Mobile Robotics & $\begin{array}{l}\text { Easy Java Simulations } \\
\text { and LabVIEW }\end{array}$ & $\begin{array}{l}\text { Virtual Lab } \\
\text { Remote Lab }\end{array}$ \\
\hline $\begin{array}{l}(2011) \\
\text { A.Rojko et al. }\end{array}$ & $\begin{array}{l}\text { Mechatronics and } \mathrm{Au}- \\
\text { tomatic control }\end{array}$ & Moodle & Remote Lab \\
\hline $\begin{array}{l}(2011) \\
\text { Carlos A.Jara et al. }\end{array}$ & $\begin{array}{l}\text { Robotics and Com- } \\
\text { puter Vision }\end{array}$ & Easy Java Simulations & Virtual Lab \\
\hline $\begin{array}{l}\text { (2011) } \\
\text { E. Fabregas et al. }\end{array}$ & Control Systems & $\begin{array}{l}\text { Simulink and } \\
\text { Easy Java Simulations }\end{array}$ & Remote Lab \\
\hline
\end{tabular}

\section{The Material and Method}

An approach that has been considered in this study covers the internet-based laboratory by implementing several elements. These elements consist of a theoretical description of the PID concept and its actual implementation for the remote development of the real plant. To be specific, several elements were included in this study, which were as follows: a Graphical User Interface (GUI) which allows users to interact with the system, an interface of the controller parameterization in PID which is tuned towards suitable gains, and a cloud storage to manage the remote access. Besides, the connection between the GUI and the controller was also established in this study. The remote interface of the controller parameterization in PID was designed to enable a simultaneous way of interacting with the plant. Meanwhile, the selected hardware components provided a simple interfacing method and a potential tool to be utilized for conducting lessons or research. Moreover, the internet-based system comprised of Arduino-Espresso8266 as the main microcontroller and Blynk applications for the establishment of the interacting interface while providing ease of access for the end user. On the other hand, the system module comprised of an LD-Didactic temperature control which was attached to the thermocouple sensor module. The purpose of this experiment was developed in a way that the desired temperature was kept constant according to the 
recommended temperature value for the real plant. The proposed system was implemented via the LabVIEW platform to conduct a graphical programming and to establish a GUI interaction medium to the user and the Arduino-Espresso8266 as the system's microcontroller in order to remotely control the real plant.

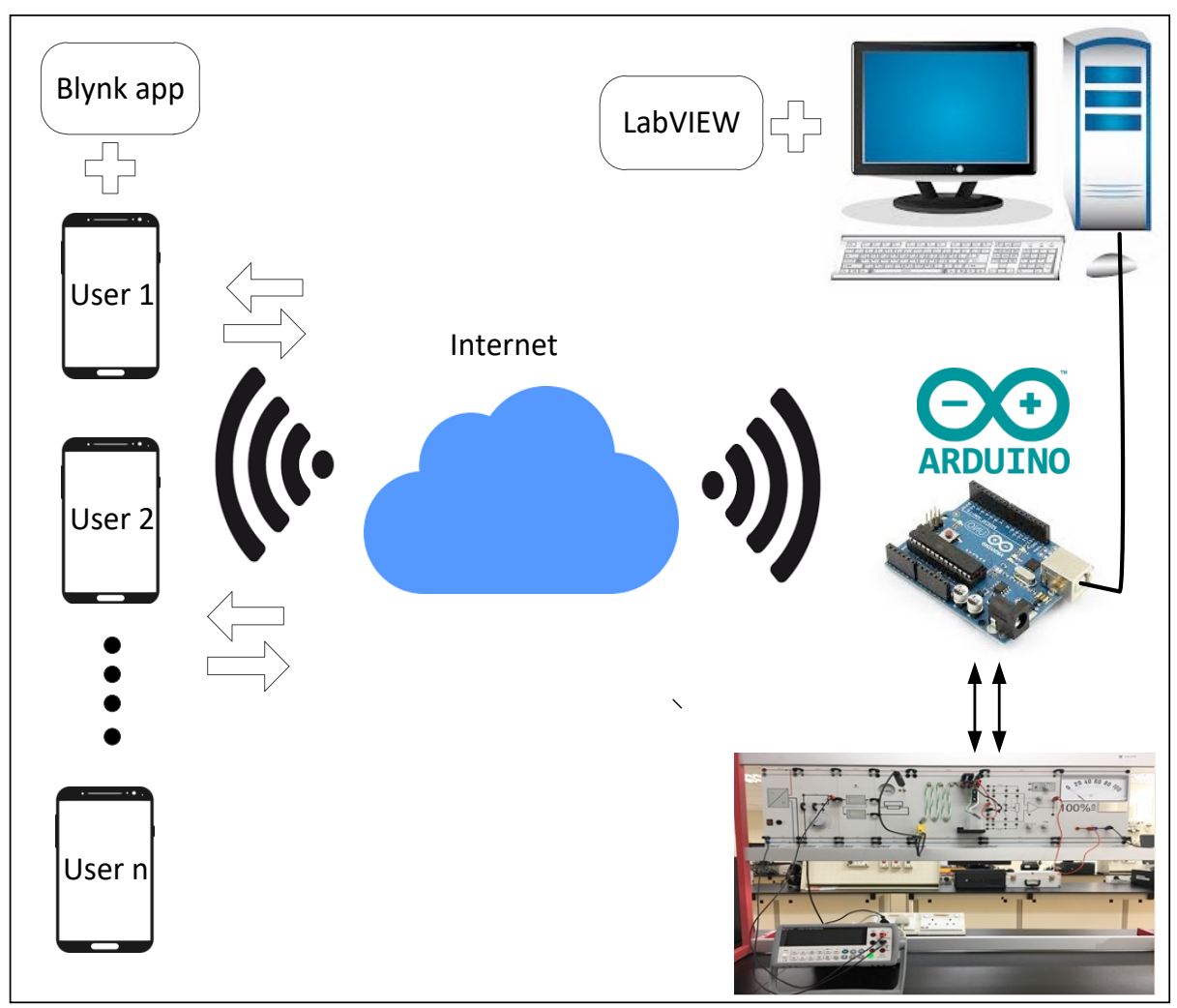

Fig. 1. The architecture of the remote laboratory

\subsection{The Description of the Plant Console}

This stage started with the development of a fragment of the overall plant using the compact and low-cost interface device to the plant. The real plant which was proposed for this laboratory's use was the LD-Didactic industrial equipment, which use was primarily for a temperature control application, as depicted in Fig. 2. For cost reduction and the provision of the similar functionality of the system, instead of using the Data Acquisition (DAQ) card, the main components used in this stage were a thermocouple and a signal conditioning element which were interfaced via Arduino-Espresso8266 microcontroller to the computer. Additionally, the reading of the temperature was recorded via the thermocouple sensor. The implementation of this controller's use facilitated the connectivity to the customized GUI platform. 


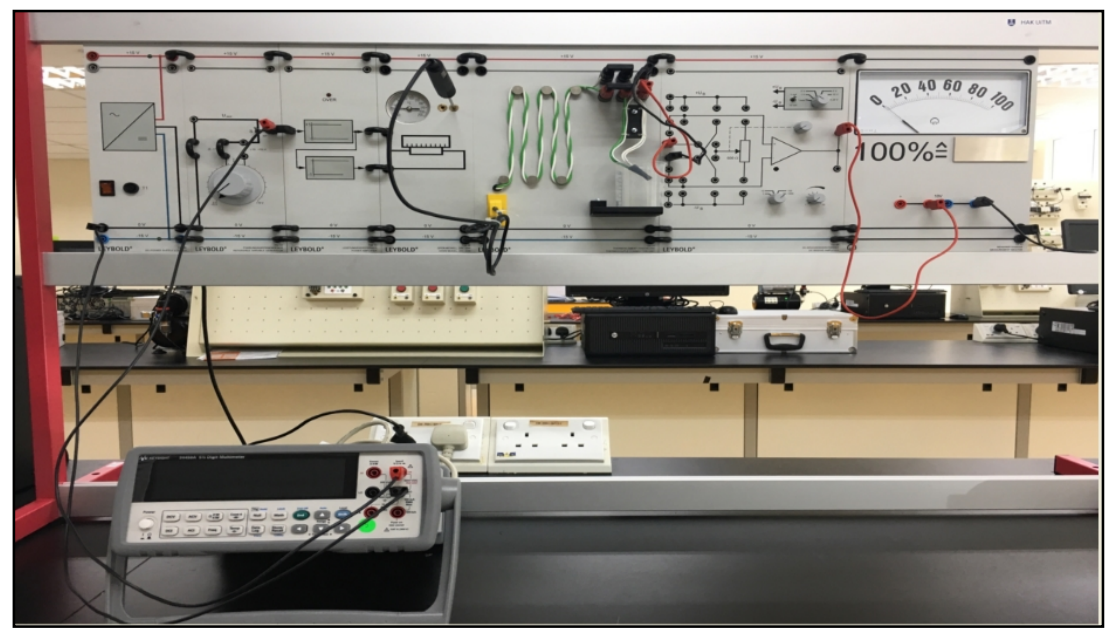

Fig. 2. The plant console of LD-Didactic equipment's temperature control

\subsection{PID Control Scheme}

A Proportional, Integral, and Derivative (PID) type of controller was selected as the control scheme for regulating the setpoint in the temperature control. The PID gains, labeled as $\mathrm{K}$, were needed for a refined design, which could be achieved through a manual tuning of the gain parameters. The gains consisted of proportional, integral, and derivative gain. The aforementioned gains were denoted by the convention of $\mathrm{k}_{\mathrm{p}}, \mathrm{k}_{\mathrm{i}}$, and $\mathrm{k}_{\mathrm{d}}$ respectively, and could be represented by the following equation:

$$
u(t)=K_{p} e(t)+K_{i} \int_{0}^{t} e^{\prime}(t) d t+K_{d} \frac{d e(t)}{d t}
$$

To demonstrate this process, the setpoint was initially set. With the switch being turned on, the initial temperature started to increase until reaching the setpoint. As the temperature increased, the PID controller regulated the temperature and stabilized in accordance with the desired temperature level.

\subsection{Internet-based Environment and the Setting for a Remote Laboratory}

The environment of the e-laboratory was designed with the Blynk application which functioned in connecting the equipment with one another through the Internet. The customized GUI was constructed via the LABVIEW application for its execution on Personal Computer (PC). It is worthy to note that a Personal Computer (PC) comprises of virtual instrument (VI) algorithms. Furthermore, the PC serves as the main monitor which can function in the offline mode and it stores the whole GUI programming data. At this point, the data regarding the temperature level, which had been sent from or to the plant, was stored and processed in the LabVIEW platform. This was followed by the process tuning of the PID controller, which was then transferred to the smartphone 
for the results to be seen. In this case, a Wi-Fi chip in Arduino-Espresso8266 microcontroller established the connection between the plant and the smartphone for the purpose of dual transmitting and data retrieval between them. In addition, with this chip, users were capable of access to the plant via smartphones in which the interface was developed through the Blynk application. Compared to the existing work of literature on the laboratory development, this framework has alleviated the development process of the Java-based algorithm. Besides, the system only involved the client-server without unnecessarily requiring the design of the host server. With this, the duration of the algorithm's development could be reduced. This indeed accelerated the learning curve due to the convenient and customizable interface platform.

In order to allow the communication of the plant to take place on the Internet, Arduino-Espresso8266 was the only provider of access to the laboratory as it acted as the gateway for the remote connection. This indicated that the Internet connection was established between the microcontroller and the plant as well as the smartphone. However, the action of monitoring via the PC served as the processing unit for the observation and direct transmission of the temperature data in the plant area. At this stage, once the connection was established and users continued with the experimentation mode, access for performing a real-time testing could be granted. In this case, students were required to reserve the slot. However, in the case of the activation of the remote simulation mode, the confirmation email which approved the experiment could be made. Additionally, the LabVIEW front display interface and the remote console interface are presented in Fig.3 and Fig.4 respectively in order to demonstrate the GUI which was designed for the system. This system comprised of the controller PID gains, namely $\mathrm{k}_{\mathrm{p}}$, $\mathrm{k}_{\mathrm{i}}$, and $\mathrm{k}_{\mathrm{d}}$.

The successful connection between the remote laboratories was determined by the installation performed on the required software such as LabVIEW, LabVIEW NIVISA, and the Blynk application. In fact, multiple points of failure are possible with the failure of one of these interfaces. However, there is a slight possibility for them to become inoperable. Therefore, in order to prevent failure of the system, the error mechanism was invented so that the connection status could be reported. This made the elaboratory operation smoother. With the report being generated, the connection between the microcontroller to the LabVIEW and the microcontroller to the Blynk application was validated. 
Paper-Computer Assisted E-Laboratory using LabVIEW and Internet-of-Things Platform as Teach...

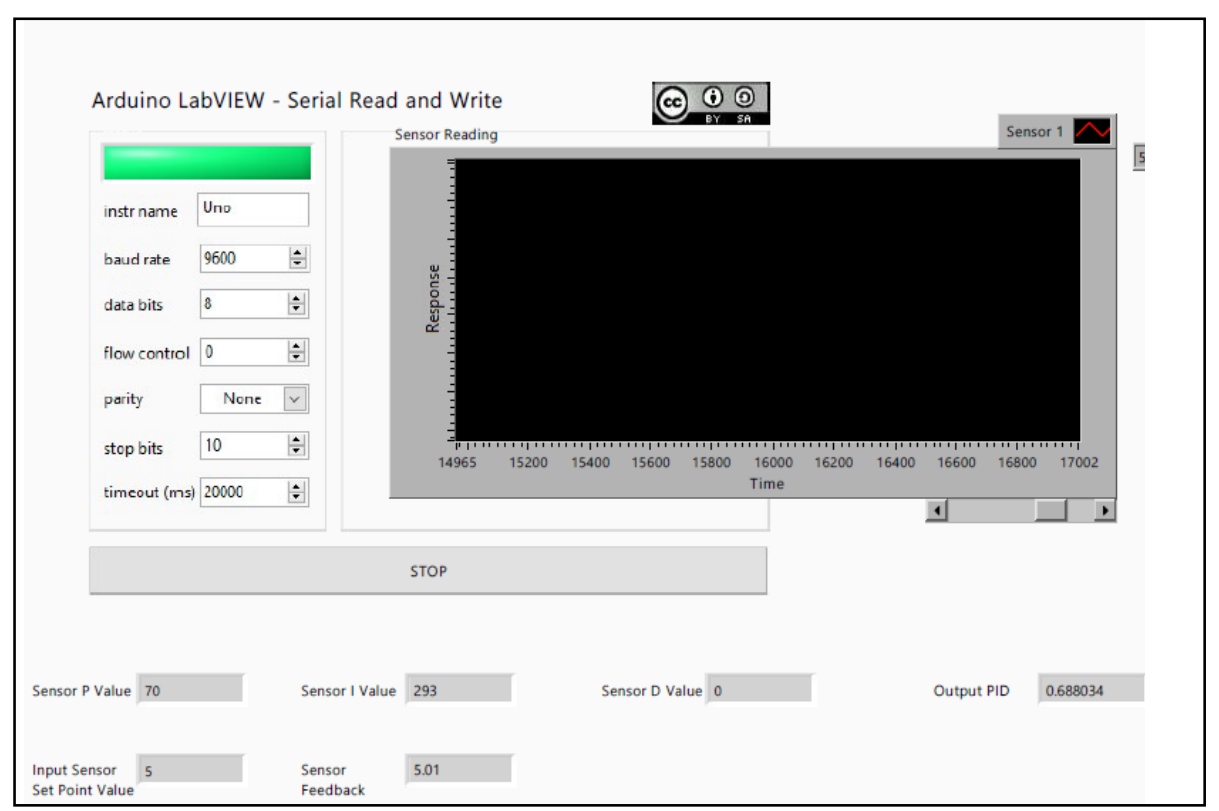

Fig. 3. Front display interface develoned usino I ahVIFW for remnte monitorino annlication

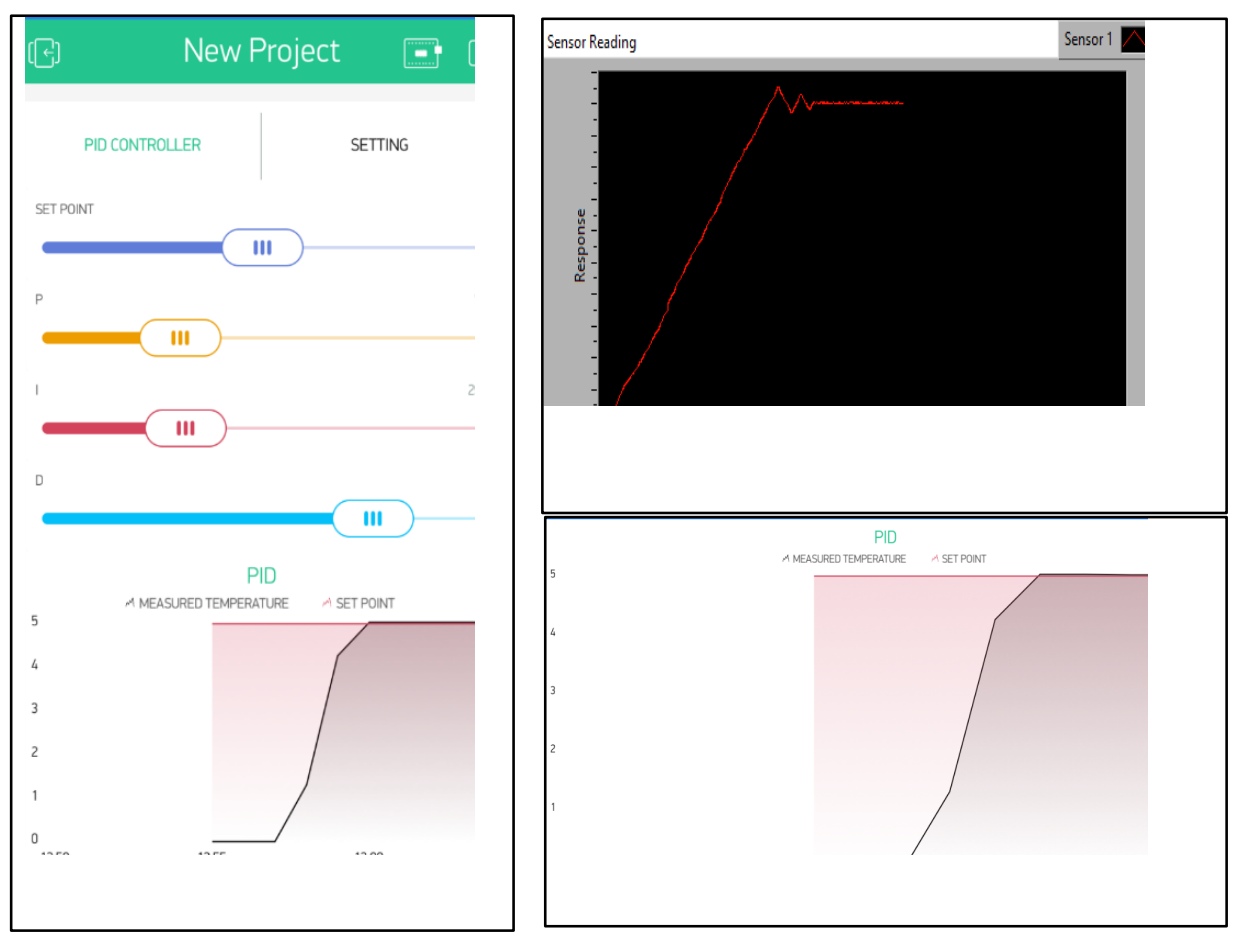

Fig. 4. Remote console interface of temperature control systems 


\section{$3 \quad$ Results and Discussions}

The simulated results of the remote laboratory are presented in Fig. 5. Through the proposed methodology, students accessed the plant via the Internet which was connected to their smartphones. As observed in the figure, the level of the temperature changed for a brief moment. Following that, the temperature was at a steady state level once the desired setpoint temperature was reached. This experiment was repeated by varying the PID gains over the real plant. During the laboratory session, students were able to manipulate the parameter gains which consisted of $\mathrm{k}_{\mathrm{p}}, \mathrm{k}_{\mathrm{i}}$, and $\mathrm{k}_{\mathrm{d}}$. Moreover, the output response retrieved from the plant could be observed. The output response which was obtained from the experiment demonstrated the effect of various parameter gains on the plant. Subsequently, the analysis could be made on the condition of the system as the parameter gains, which changed due to the manipulation of the aforementioned controller gains. Meanwhile, the tuning process was conducted based on a trial and error judgment which was tested until the optimum performance of this process was achieved. As this study was conducted for learning purposes, the tuning process allowed students to learn and understand the basic concept of PID via tuning procedure. Through this understanding, the best parameter gains could be found and the most optimal system performance could be achieved.
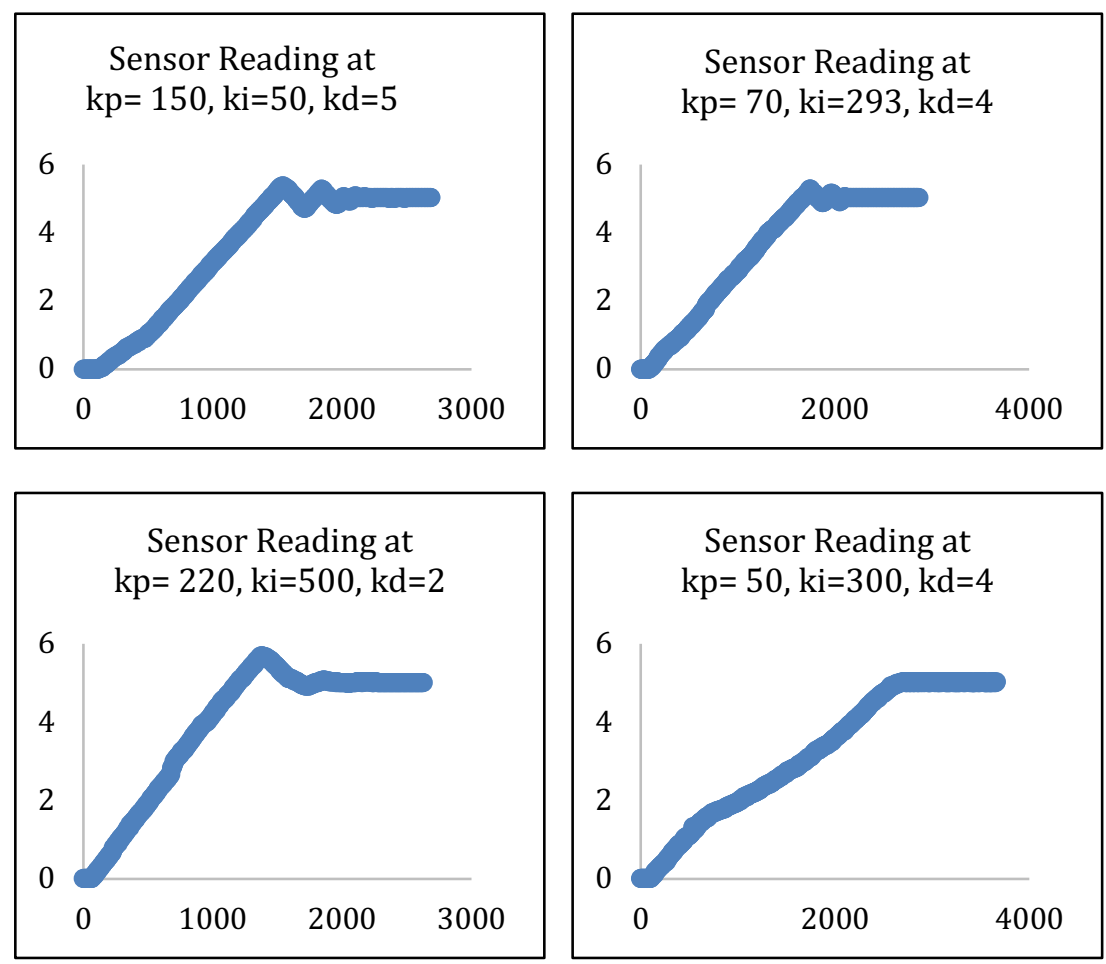

Fig. 5. The results of the evaluation of PID controller's performance from the plant console 


\section{Evaluation of the Students Learning Experience}

The accomplished e-laboratory involved a group of students who took the Industrial Instrumentation course under Diploma of Electrical Engineering in Universiti Teknologi MARA. The sample students composed of 55 total number of students who were placed in three different classes, namely class 1 , class 2 , and class 3 . The laboratory session utilized the remote laboratory as a part of teaching syllabus which had been implemented in the diploma program. Prior to the implementation of the teaching methodology, the traditional instructional method had been adopted for the collection of the experimental data from the plant to be performed manually. Furthermore, the teaching methodology was capable of instilling self-dependency in the students when they were carrying out the experiment. Through the assistance provided by the computer and smartphone interface, instructors could guide students in evaluating the optimal performance which was achieved through the changing gains of the parameter. Therefore, it can be concluded that this level of performance has definitely improved the delivery of instructional method compared to the old-fashioned instructional method where the full instructional guide is implemented on students. Besides, the GUI which was developed in the smartphone allows students to use the try-and-error method when deciding on the particular controller gain which is suitable for designing the plant. Additionally, the conduciveness of handling an experiment remotely in a real-time feedback will increase the interactivity of the teaching environment. Not only that, a more interesting teaching environment can be created, where students will be equipped with the capabilities to design and analyze the performance of the temperature plant.

Table 2. Tabulation of results of the students' involvement in the e-laboratory

\begin{tabular}{|c|c|c|c|c|c|c|c|}
\hline \multirow[b]{2}{*}{ Question } & \multicolumn{5}{|c|}{ Scale } & \multirow[t]{2}{*}{ Mean, $\bar{x}$} & \multirow{2}{*}{ SD, } \\
\hline & 1 & 2 & 3 & 4 & 5 & & \\
\hline $\begin{array}{l}\text { Do you find the e-lab easy to be han- } \\
\text { dled? }\end{array}$ & 0 & 1 & 12 & 32 & 10 & 3.927 & 0.684 \\
\hline $\begin{array}{l}\text { Are you satisfied with the practical ex- } \\
\text { perience through the internet? }\end{array}$ & 0 & 0 & 8 & 40 & 7 & 3.982 & 0.522 \\
\hline $\begin{array}{l}\text { How do you rate the implementation of } \\
\text { the remote laboratory? }\end{array}$ & 0 & 3 & 13 & 30 & 9 & 3.818 & 0.765 \\
\hline $\begin{array}{l}\text { The e-laboratory can be considered as a } \\
\text { mechanism for self-learning. }\end{array}$ & 0 & 1 & 13 & 30 & 11 & 3.927 & 0.7097 \\
\hline
\end{tabular}

A set of questionnaires which consisted of four questions are presented in Table 2. The Likert scale readings which ranged from the value of 1 to 5 represented the ratings which ranged from "most disagree" to "most agree". According to the table above, it was indicated that $58.2 \%$ of the students rated the e-laboratory to be user-friendly. It was also revealed that approximately $72.7 \%$ of the students expressed their satisfaction in the e-laboratory they experienced through the Internet. Moreover, $54.5 \%$ of the students agreed with the implementation of the remote laboratory. As for the last questionnaire, which was regarding the consideration of the laboratory as a mechanism for selflearning among students, $54.5 \%$ of them had given a positive agreement on this matter, 
besides being able to gain hands-on practices from the laboratory. Therefore, it can be said that, in overall, more than $50 \%$ of the students agreed on the adoption of e-laboratory in their course outline. This observation can also be seen through the measurement recorded from the average Mean and Standard deviation, which was confirmed to be at 3.9135 and 0.67 respectively.

Based on the assessment of students' satisfaction presented in Fig. 6 and Fig. 7, the outcomes obtained from the practical e-laboratory have supported these findings. The satisfactions/dissatisfactions expressed by the students in the survey of this study are listed as follows:

- Limited internet connection

- More experiment should be conducted so that theories and practices can be related

- It is recommended that the lab session is conducted right after the learning session for the topics related to the course

- More explanation needs to be provided on the errors which might have occurred during the experiment

- Extra exercise or experiment needs to be conducted in the LabVIEW

- The exact method of operation of the laboratory is not known in detail

As a result, it was found that majority of the students, which comprised of $87.3 \%$ of them, had full interests and understanding of the PID design process which was applied throughout the time when e-laboratory was conducted. The factors of their interests and understanding of the PID design process will be used for further improvement of elaboratory in the future. This has definitely increased the students' awareness and their learning performance.

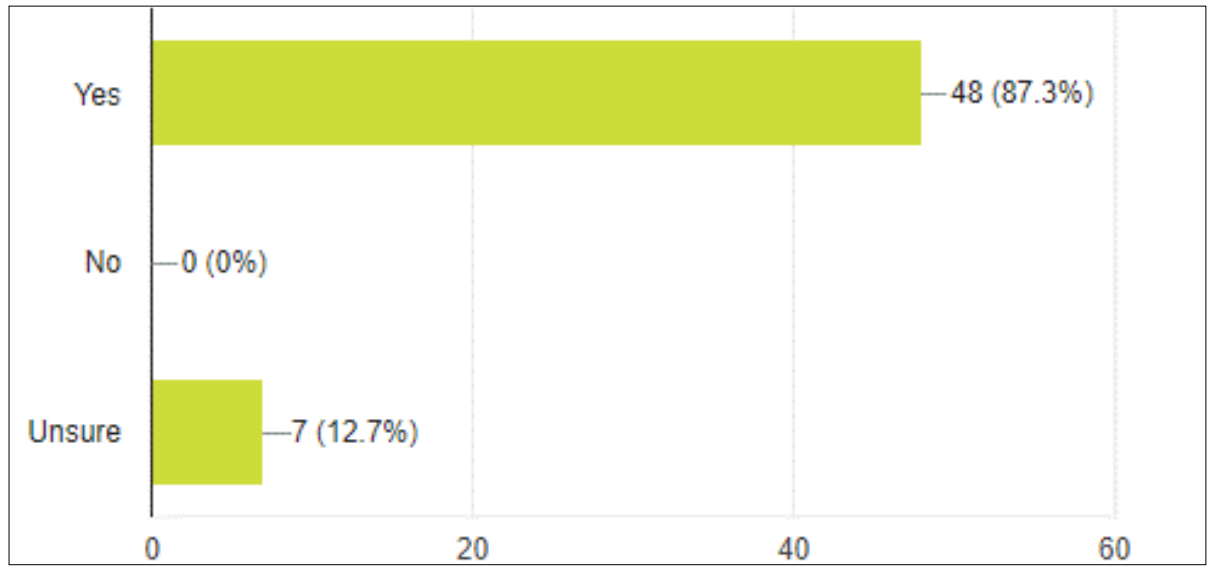

Fig. 6. The results of students' experience in the practical e-laboratory for comprehension of the subject focused on this study 


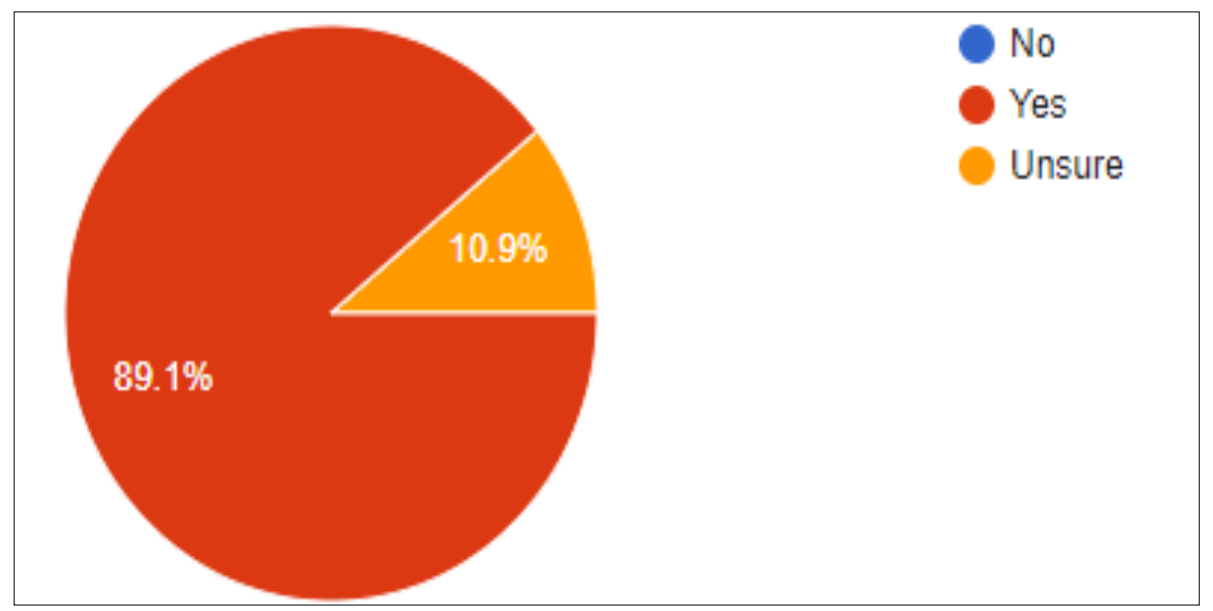

Fig. 7. The results of students' satisfaction level in the practical e-laboratory

\section{Conclusion}

This article has shown the key technologies utilized in the IoT for the remote development of the real plant. In conclusion, the study written in this article has described the approach implemented for developing the interactive remote laboratory, which is by applying the concept of regulating the temperature level of the actual plant. In this study, the interface of a LabVIEW software with Arduino-Espresso8266 enabled a configurable internet access to the setup plant. Furthermore, the laboratory experiment was designed for a remote access to the actual plant, which was performed online. The technique proposed in this study has developed the students' creativity and initiative through the controller design. This development was achieved specifically through PID tuning and comparison of the theoretical results, including the experimental application of the system function. Moreover, the proposed technique can be innovated for a further improvisation of the traditional equipment used in the laboratory. This equipment can complement the teaching methodology by providing hands-on skills in the control system theory. It is worthy to note that the framework discussed in this article can be implemented in other types of experiment platforms, as long as they are related to industrial process and control systems. Last but not least, further improvement will be done on the remote interface of smartphones into a standalone application and web-based system which enable a better, faster, and secured access to the e-laboratory.

\section{Acknowledgment}

The work has been fully supported by Universiti Teknologi MARA under the Academic and Research Assimilation (ARAS) Phase 1/2016 research grant with Project No. 600-IRMI/DANA 5/3/ARAS (0079/2016). 


\section{$7 \quad$ References}

[1] Lee, I. and Lee, K, "The Internet of Things (IoT): Applications, investments, and challenges for enterprises", Business Horizons, 2015, vol. 58, no.4, pp. 431-440. https://doi.org/10.1016/j.bushor.2015.03.008

[2] Potkonjak, V., Gardner, M., Callaghan, V., Mattila, P., Guetl, C., Petrović, V. M., and Jovanović, K. "Virtual laboratories for education in science, technology, and engineering: A review", Computers \& Education,2016, vol. 95, pp. 309-327. https://doi.org/10.1016/j.compedu.2016.02.002

[3] Asraf, H.M., Dalila,K.N., Hakim, A.M., and Hon, R. M. F. "Development of experimental simulator via Arduino-based PID temperature control system using LabVIEW", Journal of Telecommunication, Electronic and Computer Engineering (JTEC), 2017, vol.9(1-5), pp. 53-57.

[4] Loro, F. G., Macho, A., Sancristobal, E., Artacho, M. R., Díaz, G., and Castro, M. "Remote laboratories for electronics and new steps in learning process integration", In Remote Engineering and Virtual Instrumentation (REV), 2016 IEEE 13th International Conference on. IEEE, 2016, pp. 112-117.

[5] Riaño, D., Real, F., and Alonso, J. R. "Improving resident's skills in the management of circulatory shock with a knowledge-based e-learning tool", International journal of medical informatics, 2018, vol.113, pp. 49-55.

https://doi.org/10.1016/j.ijmedinf.2018.02.006

[6] Chen, X., Song, G., and Zhang, Y. "Virtual and remote laboratory development: A review", In Earth and Space 2010: Engineering, Science, Construction, and Operations in Challenging Environments, 2010, pp. 3843-3852.

[7] Dormido, R., Vargas, H., Duro, N., Sánchez, J., Dormido-Canto S., and Farias, G. "Development of a web-based control laboratory for automation technicians: The three-tank system", J. IEEE Transactions on Education, 2008, vol. 51, pp. 35-44. https://doi.org/10.1109/TE.2007.893356

[8] Domingues, L.,Rocha, I., Dourado, F., Alves, M. M., and Ferreira, E. C. "Virtual laboratories in (bio) chemical engineering education", J. Education for chemical engineers, 2010, vol. 5, no 2, pp. e22-e27.

https://doi.org/10.1016/j.ece.2010.02.001

[9] Fabregas, E., Farias, G., Dormido-Canto, S., Dormido, S. and Esquembre, F. "Developing a remote laboratory for engineering education", J. Computers \& Education, 2011, vol. 57, no 2, pp. 1686-1697. https://doi.org/10.1016/i.compedu.2011.02.015

[10] Jara, C. A., Candelas, F. A., Gil, P., Torres, F., Esquembre, F., \& Dormido, S. "Ejs+ EjsRL: An interactive tool for industrial robots simulation, Computer Vision and remote operation", Robotics and Autonomous systems, 2011, vol. 59, no 6, pp. 389-401. https://doi.org/10.1016/j.robot.2011.02.002

[11] Rojko, A., Hercog, D., \& Jezernik, K. "E-training in mechatronics using innovative remote laboratory", Mathematics and Computers in Simulation, 2011, vol. 82, no 3, pp. 508-516. https://doi.org/10.1016/j.matcom.2010.10.017 
[12] Chaos, D., Chacón, J., Lopez-Orozco, J. A., \& Dormido, S. "Virtual and remote robotic laboratory using EJS, MATLAB and LabVIEW", Sensors, 2013, vol. 13, no 2, pp. 2595-2612. https://doi.org/10.3390/s130202595

[13] Sänchez, J., Dormido, R., Duro, N., Fernändez, I. and Dormido, S. “A Virtual Laboratory for Tubular Photobioreactors for Outdoor Microalgae Culture”, IFAC Proceedings Volumes, 2013, vol. 46, pp. 297-302. https://doi.org/10.3182/20130828-3-UK-2039.00066

[14] He, Z., Shen, Z. and Zhu, S. "Design and implementation of an internet-based electrical engineering laboratory", ISA transactions, 2014, vol. 53, no 5, pp. 13771382. https://doi.org/10.1016/j.isatra.2013.12.035

[15] Esquembre, F. "Facilitating the Creation of Virtual and Remote Laboratories for Science and Engineering Education", IFAC-PapersOnLine, 2015, vol. 48, no 29, pp. 49-58. https://doi.org/10.1016/j.ifacol.2015.11.212

[16] Botero, M. L., Selmer, A., Watson, R., Bansal, M. \& Kraft, M. "Cambridge weblabs: A process control system using industrial standard SIMATIC PCS 7”, Education for Chemical Engineers, 2016, vol. 16, pp. 1-8. https://doi.org/10.1016/j.ece.2016.04.001

[17] Cotfas, P.A. \& Cotfas. D.T. "Design and implementation of RELab system to study the solar and wind energy", Measurement, 2016, vol. 93, pp. 94-101. https://doi.org/10.1016/j.measurement.2016.06.060

[18] Wang, N., Song, G. \& Chen, X. "Framework for Rapid Integration of Offline Experiments into Remote Laboratory", International Journal of Online Engineering(iJOE), 2017,vol.13, no 12, pp.192-205.

https://doi.org/10.3991/ijoe.v13i12.7738.

[19] Wang, N., Zhu, J., Lan, Q., Chen, X., Song, G. \& Parsaei, H. "Integration of a remote PID motor speed control experiment with teaching in engineering education", Engineering Education Letters, 2017, no 1, p.1. https://doi.org/10.5339/eel.2017.1

[20] Wang, N., Chen, X., Lan, Q., Song, G., Parsaei, H.R. \& Ho, S.C. "A novel Wiki-based remote laboratory platform for engineering education", IEEE Transactions on Learning Technologies, 2017, vol. 10, no 3, pp.331-341.

[21] Wang, N., Chen, X., Song, G., Lan, Q. \& Parsaei, H.R. "Design of a New Mobile-Optimized Remote Laboratory Application Architecture for M-Learning”, IEEE Trans. Industrial Electronics, 2017, vol. 64, no 3, pp.23822391.

\section{Authors}

Muhammad Asraf H. is with the Department of Computer, Faculty of Electrical Engineering, Universiti Teknologi MARA, Johor, 81750 Masai, Malaysia (masraf@johor.uitm.edu.my)

Nur Dalila K.A. is with the Department of System, Faculty of Electrical Engineering, Universiti Teknologi MARA, Johor, 81750 Masai, Malaysia (nurdalila306@johor.uitm.edu.my) 
Paper-Computer Assisted E-Laboratory using LabVIEW and Internet-of-Things Platform as Teach...

Zakiah M.Y. is with the Department of System, Faculty of Electrical Engineering, Universiti Teknologi MARA, Johor, 81750 Masai, Malaysia (zakiah9018@johor.uitm.edu.my)

Amar Faiz Z. A. is with the Faculty of Engineering Technology, Universiti Teknikal Malaysia, Melaka, 76100 Durian Tunggal, Melaka, Malaysia (amarfaiz@utem.edu.my)

Nooritawati M.T. is with the Department of Computer, Faculty of Electrical Engineering, Universiti Teknologi MARA, 40450 Shah Alam, Selangor, Malaysia (noori425@salam.uitm.edu.my)

Article submitted 09 June 2018. Resubmitted 12 September 2018. Final acceptance 22 November 2018. Final version published as submitted by the authors. 